\title{
MJMR TO LEAVE OR TO LIVE: UNDERSTANDING THE LIVED EXPERIENCES OF THE OUT OF SCHOOL YOUTHS VICTIMS OF THE TYPHOON HAIJAN IN CAPUTATAN NORTE, MEDELLIN, CEBU
}

\author{
Julius C. Dańoa \\ Cebu Normal University-College of Nursing,Philippines \\ Corresponding Author's Email:juliuscoloniadano@gmail.com
}

\begin{abstract}
The purpose of this research was to explore the lived experiences of the out of school youths (OSY) victims of the Typhoon Haijan in Caputatan Norte, Medellin, Cebu. A qualitative methodology using a phenomenology framework was employed, with semi-structured interview to facilitate the respondents reveal their lived experience. A convenience sample of five OSY's who have direct experience of typhoon Haijan was needed to reach saturation. Data analysis was based on Colaizzi's methodology. The whole process was based on the data, transcribed interviews, sorting, categorizations (cool analysis), categories as thematized (warm analysis) in a repertory grid or a dendogram that paved the way to discovering the value of the lived experiences of the out-of-school-youths victims of typhoon Haijan. The description of the lived experience revealed is the terrifying experience that emanate from the OSY internal and external environment of retreating, revealing and regressing experience,the destructive experience that derives from the OSY's understanding of detrimental, desuetude, and destitute observations, andthe surviving experience that stems from exodus, endure, and empower experience. The themes, whichemerged, suggest that the lived experience reflected a normal adaptation response of human beings siege with disasters.
\end{abstract}

\section{INTRODUCTION}

Disaster is any natural or man-made event that causes a level of destruction or emotional trauma exceeding the abilities of those affected to respond without community assistance (Allender et al., 2010).According to the Sunstar Newspaper report (November 9, 2013), typhoon Yolanda that strikes many parts of the Visayas region in the Philippines causes a disaster that really affects many vulnerable populations. The destruction of the environment by Typhoon Yolanda resulted in injuries, deaths and property destruction especially the vulnerable populations. Vulnerable population are groups who have a heightened risk of higher mortality rates, less access to health care, are uninsured and underinsured, have a lower life expectancy, and an overall diminished quality of life (Shi \& Stevens, 2004). According to Mechanic \& Tanner (2007), vulnerability stems from developmental problems, personal incapacities, disadvantaged social status, inadequacy of interpersonal networks and supports, and the complex interactions of these factors over the life course.

One part of the vulnerable population is the out-ofschool-youths. The youth is the critical period of person's growth and development from the onset of adolescents towards the peak of mature, self-reliant and responsible adulthood (RA8044). However, the out-of- school, or disconnected youth are young people that lack a high school diploma and are not enrolled in school and are detached from work(CLASP, 2001).According to Jill Lawler (2011), children and youths are vulnerable to disasters. As Mechanic and Tanner (2007) describe it, these out-of-school-youths are disadvantaged social status, with personal incapacities, and inadequate interpersonal supports and networks. However, there are insufficient research findings focusing on the lived experiences of the out of school youths.

For nurses working with disadvantage populations such as the OSY's, it is very challenging and strenuous and the intuitive distress should be expected and addressed. According to Frank \& Sullivan (2008), feelings of guilt sometimes surface when nurses contrast their own life experiences with those of their clients and future programs and projects are crafted to come up preventive action plans to mitigate disaster responses and promote resiliency in the community. By understanding the experiences of these OSY's, the nurses will be able to prepare for future catastrophic situations where the nursing services will be required. Thus, the nurse researcher intends to explore the lived experiences of the vulnerable out-of-school-youths (OSY's)in Barangay Caputatan Norte, Medellin, Cebu 
and are victims of Typhoon Haijan.Particularly, this study sought to answer the question "What horrible situations do the OSY experience during the landfall of typhoon Haijan?" that are eidetic in nature based on the fascinating stories of OSY affected by the Typhoon Haijan.

\section{METHODOLOGY}

\section{Research Design}

Phenomenology is the philosophical approach employed in this research study. Each differing philosophical approach grew out of a particular view of what it means to be human and to be in the world in which we live (Caelli, 2001). The word phenomenology is derived from the Greek words phainoemn, meaning appearance, and logos, meaning reason. According to Acosta (2010) phenomenology is a "reasoned inquiry which discovers inherent essences of appearances and intuition of the felt sense.

\section{Selection and Study Sites}

In collaboration with the local government of Barangay Caputatan Norte, Medellin, Cebu and the Center for Research and Development of Cebu Normal University, selection of these respondents is based on the purpose of the research for which Kruger (1988), recommended to look for those "who have had experiences relating to the phenomenon to be researched." Respondents were the out-of-school youths victims of the super typhoon Haijan, age 15 to 30 years old and male or female residing in Barangay Caputatan Norte, Medellin, in the Province of Cebu, Philippines. They are not attending school especially in the secondary and collegiate level and still lives with their parents. The Barangay Caputatan Norte, Medellin was also a victim of the super typhoon Haijan(PRRMC, 2014) and the participants of the study are registered residents.

\section{Data Gathering Procedure}

Patton (1990) recommended three qualitative interviewing processes, namely: formal, conversational and semi-structured interviews. In this study, the semistructured interview was facilitated as the main source of data collection to help respondents reveal their lived experience with respect to the frame of thoughts and structure of their responses. Semi structure interviews develop friendly rapport between interviewer and interviewees evading strange feelings of hesitation. Through interview the subjects can easily express their inner thoughts of their real life experiences (Knox \&
Burkard, 2009).

\section{Interview procedure and ethical consideration}

Close question or open-ended questions were medium in finding individual's variation of his or her lived experiences. Questions were directed to the interviewees' experiences, feelings, beliefs and convictions geared toward achieving the purpose of the research study. The study was duly approved by the research ethics committee with the notice to proceed provided by the University's Center for Research and Development. The researcher proceeded to the sample site and a permit was granted by the Barangay Captain who is the head of the community in order to be acknowledged and get support to conduct the study in their respective locality.

Written consent from the respondents was the foremost procedure prior to the interview. The parents were informed before the consent was signed. The interviewer sought approval for note-taking and for audio and video recording when the interview took off(see Appendix II). As it is a procedure in phenomenological research like intuiting, analyzing and describing, the subjects were requested to elaborate further on their experiences should certain questions were found to be interesting and worth-knowing. When the researcher felt that experiences being researched on were fully described and articulated, the researcher must have the ability to close the interview politely and with ease giving assurance to respondents that their responses were treated with utmost confidentiality. The language in the interview used was the local dialect Cebuano since all participants cannot comprehend the English language. However, the transcriptions were interpreted from Cebuano into English by an English Professor.

\section{Explicitation of Data}

Guided by the principle of bracketing or reduction (Gearing, 2004), results of the interview were treated in this manner. Three forms of bracketing were used namely: Descriptive bracketing translated concepts from phenomenological philosophy to the phenomenological research. It allowed the researcher to clearly set aside the base majority of personal suppositions and hold in abeyance most external suppositions, thereby focusing on the pure essences of the phenomenon. Existential bracketing tried to seek the essence of the story that can be referred to the coding of data into themes, analyzed in order to uncover the central meaning of the "essence" (Lebenswelt) of the phenomenon/ pragmatic bracketing was more open to the researcher's interpretation and 
design. It can be practiced across qualitative transitions and settings but requires clear forethought and construction from the researcher. In other words, it is the suspension of all judgments of what is real (Lewis, 2015).

The whole process was based on the data, transcribed interviews, sorting, categorizations (cool analysis), categories as thematized (warm analysis) in a repertory grid or a dendogram that paved the way to discovering the value of the lived experiences of the out-of-schoolyouths victims of typhoon Haijan. The researcher followed the steps of analysis as proposed by Colaizzi in 1978 (Shosha, 2012). First step: Repetitive reading analysis; in order to grasp the whole idea or opinions of the interviewees. In this step the researcher sensed the "feeling" for the materials. The focus was to single out relevant psychological phenomena without the purpose of testing the validity of any particular hypothesis. The second step: Extraction of highlighted responses (Lebenswelt) from each participant. The researcher distinguishes 'small units' called the meaning units. No revisions on grammatical errors that may be found. Third step: Decoding key responses (by participant number under each interview question. Keywords and phrases within each response were highlighted. The researcher transformed each meaning unit from the language of the interviewees (emic) to the language of the researcher (etic). Step four: Formulation of categorical themes. The researcher sought to describe 'how' (noeses) the phenomenon express itself and 'what' (noema) the phenomenon is. Step five: identifying the 'emergent themes' underpinning the relevance to the target study. Each theme was labelled as succinctly and accurately as possible to maintain interviewees' ideas while showing their participation in the common idea. Once final analysis was done, the researcher presented this to the peer review process, a practice called 'member checking'. These techniques served as feedback to ensure trustworthiness of the captured findings. (McWillian et al., 2009).

\section{RESULTS AND DISCUSSIONS}

This phenomenological study describes the individual and collective experiences of a select group of out-ofschool youths (3 OSY males and 2 OSY females) that addresses relative to the main question: "What horrible situations do the OSY experience during the landfall of typhoon Haijan?" Interestingly, the human experience of disasterof the OSY's revealed fascinating occurrences which is categorized into three (3) phases. The first phase is the terrifying experience that emanate from the OSY internal and external environment of retreating, revealing, and regressing experience.Consequently, the second phase is the destructive experience that derives from the OSY's understanding of detrimental, desuetude and destitute perception. The third phase is the surviving experience that stems from of exodus, endure, and empower experience. The results is presented in a pyramid figure as the phases of disaster experiences of the OSY ascends from terrifying experiences, destructive experiences and the surviving experiences.

\section{Terrifying Experience}

Terrifying experience operates in the context of disasters. Every human being is frightened and will suffer enormous fear to disasters most especially to strong typhoons. The out-of-school-youth are most frightened due to their fragile intellectual and emotional capacities. On the time of encountering the typhoon Haijan, a retreating thought comes to the mind of the desperate OSY's. To retreat or withdraw is the first course of action in order to position them from danger. They say:

"Everybody was hiding. We were all scrambling and trying to hide.(Y3)

They went back inside their houses. ((Y4)

When I could no longer bear it, I ran for home." (Y5)

At the time the OSY's position themselves from danger, they encountered a profound observation that made them realized and learned from the dreadful event. This disclosure is the revealing experiences that they perceived. They expressed:

"People came to check the damages. The Typhoon Yolanda was very strong.

I was so afraid. As I was running, I feel like I could be blown away. I was afraid that I could not cross the bridge.(Y1)

I was so afraid and I had goosebumps on my body."(Y5)

When the strong typhoon keeps on striking the OSY'S, it gives them the feeling of helplessness and desperation. This times the OSY's retreat themselves to earlier levels of development or to infantile tendencies. The OSY's experience the infantile tendencies or a regression personality. The regression personality usually seeks protection from the older persons by hiding from them. They expressed:

"When our father told us to evacuate, we just obeyed 
his instructions because we still don't know what to do." $(Y 2)$

When that was happening, I asked, "What's happening, pa?" Then he replied, "You should evacuate." He said also that a storm was coming and we were trembling withfear." (Y4)

\section{Destructive Experience}

The destructive experience elucidates contexts of demolition and havoc brought about by typhoon Haijan. The OSY's destructive experience perceived as detrimental to their lives. Witnessing the devastation in their environment, there inabilities to respond to the difficult situation and the hopelessness of the situation becomes injurious and hurtful to their lives. They say:

"The wind was already blowing hard and I was on my way. The roof the market was blown away. The trees were destroyed and most of the vehicles were turned upside down. Some of the vehicles were pinned down.A coconut tree fell and crushed our house. The roads were being blocked by the debris and the flood.I saw houses being blown away.(Y1)

When Yolanda hit our place, houses were blown away and we were very afraid since we have to evacuate.(Y3)

In here sir, the metal roofs were flapping due to the strong winds." (Y4)

With the destruction of their environment, the OSY's see their hopes and dreams shattered and felt they are in a state of desuetude. They sensed their lives were uselessand thought of nowhere to go and hide because everything seems not usable. They expressed as:

"If ever this barangay hall will be destroyed, where will we go? The wind blew our house very hard to the point that our house was like being lifted in the air. (Y2)

We ran to our neighbor's house but their house was also struck by the strong wind. We were about to go back to our house but everything was destroyed. "(Y3)

With the feelings of being useless, a state of destitute was also revealed. The physiological and psychological need which is food, water, housing, and their farms is not available, that causing them to feel impoverished. The typhoon Haijan destroys their farms which is the primary source of their livelihood.They say:

"Our corn plants sir... we were happy sir because they are big and they were green and nice to look at.
Everything was destroyed when Typhoon Yolanda came. It can't be eaten anymore. The corn stalks stopped growing because they were uprooted." (Y3)

"It was very difficult and hard before the relief operations came. Because we are hungry and water and food were short to supply enough for us. "

"We were having a hard time locating the water pump because of the fallen trees and scattered debris. We were only poor and have nothing and I was just hoping that someone will help us so that we may be able to recover from this tragedy."(Y5)

\section{Surviving Experience}

According to Rick Daniels, Grendel \& Wilkins (2008), every human being responds physiologically, behaviorally and cognitively to prevent or minimize unpleasant or harmful experiences that challenge ones personal resources. Persons use their coping strengths in specific ways depending on whether the situation is normal or difficult. According to Updegraff \& Taylor (2000), for other individuals, a traumatic experience can serve as a catalyst for positive change, a chance to re-examine life priorities or develop strong ties with friends and family and moreover it reordered priorities may translate into changes in activities. The OSY's in typhoon Haijan have three surviving experiences that stems from exodus, endure and empower experience. The exodus is the first coping response at the height of typhoon Haijan by the OSY's. During the onset of the typhoon Haijan, the initial OSY's reaction was to run away from danger since they find their houses not protective enough to cover them. For them, security is attained if they hide to a safer ground.Fear is a normal emotion, and its purpose is to alert us to potential danger which is necessary for adaptive survivability. (King \& Tarrant, 2013)They say:

"If ever this chapel would also get destroyed, where would we evacuate next?" We would go to the mayors building." (Y1)

"Just before the typhoon wasn't that strong, we already evacuated at the evacuation center. We went here at the barangay hall. Our neighbors were already telling us to evacuate because the typhoon will be stronger sir. So, we evacuated." (Y2)

"We decided to transfer so as to avoid any accidents that might happen to us. The storm was getting strong and people started to evacuate crowding the 
place."(Y3)

The OSY's endure the threats of the typhoon. They endure earnestly by tolerating the hardships of hopelessness and desperation. This covert emotion focused coping is a way of attempting to solve threats to ego integrity (Aguilera, 1997). They expressed as:

"We didn't bring our stuffs sir. We just secured it in a safe place so that whenever we would return to our house, we can still retrieve some of our things. "(Y1)

"When our father told us to evacuate, we just obeyed his instructions because we still don't know what to do." (Y3)

Typhoon Haijan brought positive impact to the lives of the OSY's. It makes them stronger and confident especially in controlling their life and claiming their rights (Oxford Dictionary, 2015). This empowering force is a means to survive the not so good experiences brought about by the disaster. The influences that increase their assertion of change are getting an education and engage in small business enterprise.King \& Tarrant (2013) describes the individual that believes in education can generate the better understanding of the world and may visualize any events that led to coping. They claimed:

"I will study well sir so that I will be able to reach my dreams of becoming a policeman (Y1).

"I will look for a job sir and help my mother."

"I would still prepare sir if typhoon would strike again like our neighbors; they planted trees (Y2)."

"I will strive hard to finish schooling and to work as stewardess or a police so that I will catch those people having badvices (Y4)."

"I was 17 and I already graduated when the storm hit our place. I was able to secure a job at the camp sir. I'd wake up early sir and if ever I have a neighbor that would ask me to work on something, I would work right away so that I can earn money. I can make use of those fallen branches and made it into charcoal packed in sacks.Other branches of fallen woods were bundled and sold as firewood's (y5)."

\section{DISCUSSION}

This study explored the lived experiences of the vulnerable out-of-school-youths (OSY's) who are victims of Typhoon Haijan. Particularly, this study sought to answer the question "What horrible situations do the OSY experience during the landfall of typhoon
Haijan?"After the analysis, the themes emerged in the study were identified into three (3) phases of the OSY's experiences during the typhoon Haijan namely terrifying, destructive and surviving. In each phase, there are three sub-themes emerged. In the terrifying experience, the sub-themes identified were retreating, revealing and regressing. The destructive experience sub-themes emerged were detrimental, desuetude and destitute. The surviving experience sub-themes emerged were exodus, endure and empower.

The first phase of the OSY's experiences during typhoon Haijanis the terrifying experience. In this phase of the OSY's experience, they perceived the typhoon Haijan as fearsome and shocking. The fear and horrible situations perceived by the OSY's brought uncertainty that leads to hopelessness into their lives. The hopelessness of the OSY's is derived from beingthe disadvantaged social status with personal incapacities.(Mechanic and Tanner, 2007). The OSY's in Medellin belonged to marginalized and poor families with long standing absence in school development. They showed behavior that was frightened and alarmed as the Typhoon Haijan brought havoc to their community.

The second phase of the OSY's experience during typhoon Haijan is the destructive experience. Witnessing the devastation in their environment, there inabilities to respond to the difficult situation, their personal incapacities, and the hopelessness of the situation becomes deleterious to their lives. With the lost of their houses and farmlands, the OSY's find themselves useless and desperate thought of where to go. The inadequacies of food and water caused them to feel impoverished. This phase brings confusion and chaos to their lives because they see that all what they have is lost and destroyed.

The third phase of the OSY's experience during typhoon Haijan is the surviving experience. In any dreadful situations human encounter, human beings usually respond to prevent or eliminate unlikable experiences that challenge one's personal resources. (Daniels, Grendel \& Wilkins, 2008) Persons use their coping strengths in specific ways depending on whether the situation is normal or difficult. According to Updegraff \& Taylor (2000), for other individuals, a traumatic experience can serve as a catalyst for positive change, a chance to re-examine life priorities or develop strong ties with friends and family and moreover it reordered priorities may translate into changes in 
activities. Masten \& Obradovic (2007) found out that fundamental adaptive systems play a key role in the resilience of young people facing diverse threats. Thus,a disturbing life event can serve as a catalyst for positive change and a chance to re-examine life priorities (Updegraff \& Taylor, 2000).

\section{CONCLUSION}

The lived experience of the OSY's developed the phases of disaster experience revealed interesting happenings. The disaster experiences of the OSY's illustrated that all human beings go through the stages of adaptation. Thus, the results of the study are essential for nurses in preparing nursing care plan to OSY's

\section{REFERENCES}

Acosta, A. \& de Guzman, A. (2017). A panorama of conflict mediation experiences of a selected group of administrators representing the Philippine School Overseas. International Journal of Educational Policy Research and Review, 4 (7), pp 158-168

Aguilera, D.(1997). Crisis Intervention: Theory and Methodology. $8^{\text {th }}$ Edition, Mosby, USA.

Allender, J., Rector, C. \& Warner, K. (2010). Community Health Nursing: Promoting \& Protecting the Public's Health, $7^{\text {th }}$ Edition, Lippincott Williams \& Wilkins, USA.

Caelli, K. (2001). Engaging with Phenomenology: It is more of a challenge than it needs to be? Quality Health research, 11(2), pp 273-281.

Center for Law and Social Policy (CLASp). (2012). OutOf-School-Male-Colors. Retrievedfrom:https:// www.clasp.org/sites/default/files/public/ resourcesandpublications/files/RWJF-RoundtableSummary-OSY.pdf

Creswell, J.W. (1998). Qualitative Inquiry and Research Design: Choosing among Five Traditions. Sage Publication, USA.

Daniels, R, Grendell, R. \& Wilkins, F. (2008). Nursing Fundamentals: Caring \& Clinical Decision Making. Australia: $2^{\text {nd }}$ Edition, Cengage Learning, USA.

Frank, D. \& Sullivan, L. (2008). The Lived Experience of Nurses Providing Care to Victims of the 2005 Hurricanes. Southern Online Journal of Nursing Research, 8(3), pp1-11.

Gearing, R. (2004). Bracketing in Research: A Typology. Quality Health Research, 14(10), pp 1429-1452.
King, T.A. \& Tarrant, R.C.A. (2013). Children's knowledge, cognitions and emotions surrounding natural disasters: An investigation of year 5 students, Wellington, New Zealand. Australasian Journal of Disaster and Trauma Studies, 1, pp17-25.

Knox, S. \& Burkard, A. (2009). Qualitative research interviews. Psychotherapy research : 19, pp 566575.

Kruger, D. (1988). An introduction to phenomenological psychology. $2^{\text {nd }}$ Edition. Juta, South Africa.

Kvale, S. (2006). Dominance through interviews and dialogues. Qualitative Inquiry, 12(3), pp 480-500.

Lawler J. (2011). Children's Vulnerability to Climate Change and Disaster Impacts in East Asia and the Pacific. Published by: UNICEF East Asia and Pacific Regional Office. Retrieved from: https:// www.unicef.org/media/files/Climate_Change_Re gional_Report_14_Nov_final.pdf

Lewis, S. (2015). Qualitative Inquiry and Research Design: Choosing Among Five Approaches. Health Promotion Practice, 16(4), pp473-475.

Masten, A.S. \& Obradovic, J. (2007). Disaster preparation and recovery: lessons from research on resilience in human development. Ecology and Society 13(1), pages 9

McWilliam, C., Kothair, A., Ward-Griffin, C., Forbes, D., Leipert, B. (2009). Evolving the theory and praxis of knowledge translation through social interaction: A social phenomenological study. Implementation Science, 4(2), pp 1-14.

Mechanic, D. \& Tanner, J. (2007). Vulnerable people, groups and populations: Societal View. Health Affairs, 26(5), pp 1220-1230.

Oxford Dictionary. (2015). Oxford Dictionary Press. Retrieved from: http://www.oxforddictionaries. com/ us/definition/american_english/empower on May 4, 2015.

Patton, M. (1990). Qualitative evaluation and research methods. Sage Publications Inc, USA.

Philippine Risk Reduction Management Coordinating Council Report. (2014). Assessment of Disaster Risk Reduction and Management (DRRM) at the Local Level. Retrieved from: https://www.coa.gov.ph / phocadownloadpap/userupload/DRRM/ Assessment_of_DRRM_at_the_Local_Level.pdf.

Shi, L. \& Stevens, G.D. (2005). Vulnerability and unmet 
health care needs. The influence of multiple risk factors. Journal of General Internal Medicine, 20(2), pp148-154.

Shosha, G.A. (2012). Employment of Collaizzi's Strategy in Descriptive Phenomenology: A Reflection of a Researcher. Retrieved from: https://eujournal. org/ index.php/esj/article/viewFile/ 588/657.
Sunstar Newspaper. (2013). To Victims of the 2005 Hurricanes., Sunstar Newspaper, Cebu's Local Newspaper, Cebu City, Philippines. Retrieved from: https://www.sunstar.com.ph/CEBU.

Updegraff, J.A. \& Taylor, S.E. (2000). From vulnerability to growth: Positive and negative effects of stressful life events. Brunner-Routledge, Philadelphia. 